\title{
Materializing the "Urban Region" Concept by Integrating Ecological Networks and Central Place Theory
}

\author{
Yongzhong Guo, Youzhao Liu \\ Nanjing Agricultural University, Nanjing, China \\ Email: simonyzg@hotmail.com
}

How to cite this paper: Guo, Y.Z. and Liu, Y.Z. (2018) Materializing the "Urban Region" Concept by Integrating Ecological Networks and Central Place Theory. Journal of Environmental Protection, 9, 1314-1342. https://doi.org/10.4236/jep.2018.913082

Received: October 18, 2018

Accepted: December 8, 2018

Published: December 11, 2018

Copyright ( $\odot 2018$ by authors and Scientific Research Publishing Inc. This work is licensed under the Creative Commons Attribution International License (CC BY 4.0).

http://creativecommons.org/licenses/by/4.0/

\section{(c) (i) Open Access}

\begin{abstract}
This paper attempts to integrate urban development and ecological conservation by applying and syncretizing the "urban region" concept from landscape ecology and the "city-region" concept from socioeconomics. First, various concepts pertaining to regions are discussed and then, the integration of ecological conservation and urban development on a regional scale is introduced. Subsequently, the Greater Pearl River Delta, in China, is used as a case study area and landscape ecology's "urban region" concept is applied to produce a landscape spatial arrangement framework for an urban region. This framework is achieved through the following steps: conceiving the study area as a region that consists of two urban regions, arranging ecological conservation landscapes by establishing a regional ecological network within the urban-region rings; and formulating an urban development strategy using central place theory. The resulting landscape spatial arrangement solution includes natural protection areas that cover half of the study area, several key strategic urbanizing locations, and suggestions for the strict protection of certain agricultural land-use areas. We believe that this framework facilitates a feasible exploration of land-use planning on a regional scale, although more in-depth studies are required to refine this approach.
\end{abstract}

\section{Keywords}

City-Region, Urban Region, Ecological Network, Central Place Theory, Greater Pearl River Delta

\section{Introduction}

In human history, mankind has always found ways to utilize and change the 
surface of the earth, which belongs both to us and the flora and fauna. These activities are changing the landscapes. Negative impacts include decreasing biodiversity and landscape fragmentation, resulting in natural habitat loss, decreased landscape resilience and resistance, etc. With the exception of hunting, agriculture, and deforestation, the construction of modern urbanization and transportation infrastructure is damaging the quality and quantity of natural landscapes. This results in efforts to protect the natural environment through such measures as the creation of conservation areas, national parks, etc. However, on the other hand, for the purpose of human development, we are greedily consuming the natural land around us. Thus, we must discover a way to reconcile both sides.

For at least two hundred years, attempting to integrate human development and environmental/ecological protection issues has been an important theme among scientific researchers and landscape planning practitioners. Influential contributors include Patrick Geddes (1915) [1], Ian L. McHarg (1969) [2], Zev Naveh (2000) [3], Richard T. T. Forman (1995, 2008) [4] [5], and others.

Landscape ecology attempts to find solutions for the spatial arrangement of land to support ecosystems and human populations from a land-mosaic perspective [5]. The patch-corridor-matrix model is an effective tool for land-use planning. Often, the patch-corridor-matrix model is applied to design ecological networks (ENs) as nature protection areas, which include core areas, corridors, and buffer zones. Studies addressing theories and practices with regard to ENs have formed a large body of literature (see, for example, Battisti, 2013 [6]; Boitani et al., 2007 [7]; Hepcan \& Ozkan, 2011 [8]; Jongman, 2003 [9]; Opdam et al., 2006 [10]). On the nature side, these ENs are efficient for the building of nature conservation systems.

On the other side, for a regional-scale development strategy, the city-region concept is typically considered from a socioeconomic (human development) perspective. A city-region may be considered a geographic region composed of a core (metropolitan area) or multi-cores and surrounding areas (hinterlands) that interact with each other. There have been numerous studies concerning city-regions (see, for example, Hall \& Pain, 2006 [11]; Hall, 2009 [12]; Davoudi, 2008 [13]; Parr, 2005 [14]; Rodríguez-Pose, 2008 [15]).

Moreover, the emerging urban network/city network paradigm in addressing regional scale human urbanization issues seems promising. Influencing contributions include Camagni \& Salone (1993) [16], Batten (1995) [17], Meijers, 2007 [18], etc. These researchers argue that, within the highly urbanized areas, a region can be considered being tightly linked area which in turn connected by several (even dozens of) actively interacting urban centers through socioeconomic functions and dense traffic infrastructure. All these nodes (urban centers) and lines (infrastructure) together work as a whole-urban network.

Central place theory (CPT) is a classical settlements location theory that emphasizes the influences/relationships among different levels of settlements (e.g., 
villages, towns, cities, and metropolises). Despite its own deficiencies and criticisms, the basic principles of CPT are still valid and there are signs that CPT is about to reemerge in urban study fields (see, for example, Mulligan et al., 2012 [19]; Parr, 2002 [20]). Additionally, CPT is efficient for managing urban development strategies, although its rationale and applicability have always been criticized. Thus, on the human side, CPT can be employed as a method to design a human development (urbanization) strategy within the city-region/urban network framework for the purpose of development.

However, it looks like that there exist a dichotomy in arranging regional landscape when people try to develop human life while protect natural environment. We need a new framework integrating these two sides. This will permit a powerful synthesis that represents an improvement on the above mentioned that only dispose one of the two aspects.

Richard T. T. Forman's pioneering "urban region" concept provides a breakthrough in meshing nature protection and human development in a region from a landscape ecology point of view. This conceptualization permits the implementation of human urbanization land use, while meeting demands for nature protection within the framework of an urban region. The key concept of an "urban region" is that, based on defined urban region boundaries, regional landscape plans can be arranged from two opposite perspectives, nature protection and human development, and at the same time, can unify the two within a single urban region framework.

To coordinate the contradicting needs of both nature and humans, this study attempts to identify a feasible strategy to develop solutions for land use spatial arrangements on a regional scale that incorporates nature protection and human development. This approach is based on the "urban region" concept from a landscape ecology perspective. Land use for nature protection based onan EN and an urban development scheme based on CPT are embedded in an "urban region" framework. That is, deepening and broadening the "Urban Region" concept through network theories: ecological network and CPT based urban network.

In the sections that follow, multiple perspectives regarding regions are discussed and then, an "urban region" conceptualization for regional land-use spatial arrangements is introduced. Subsequently, the urban region concept is applied to the Greater Pearl River Delta (GPRD) using ENs as the basis for nature protection and CPT as the principle for urban development with the goal of syncretizing ecological conservation and urban development.

\section{Review of the Literature Concerning Regions}

\subsection{The Region Concept}

Geographically, a region may be depicted as a location with a measurable scope that covers a part of the earth's surface (terrestrial land and/or surface water) and includes the physical, socioeconomic, and cultural dimensions that fall within its 
boundaries. The primary criterion distinguishing regions from other geographic scales is that the elements are homogeneous within the region's boundaries but heterogeneous between regions. The elements used to define regions can be single or multiple, and the boundaries can be strictly linear or gradually transitional. The scale of a region can be as small as hundreds of square kilometers and as large as millions of square kilometers; however, the scale is typically sub-national.

Agnew (1999) [21] states that the term "region" often brings to mind the idea of a homogenous space that may be distinguished from other portions of the earth's surface by its physical and cultural features. Thus, a region exists independent of the perspective of observers and is a real entity. The world is covered with a network of identifiable areas [22]. However, a region is also a method of viewing and organizing concepts pertaining to the world [23]. A number of researchers believe that regions are based on social constructs of the world; regions may also be considered complicated constellations of agency, social relations, and power that combine material and immaterial elements [23] [24].

Generally, three main types of regions are proposed: administrative, formal, and functional. Administrative regions are artificially delimited spaces with administrative/political borders, such as county or province boundaries, for administration purposes; formal regions are uniform areas based on a classification of the area's geographical, human, and physical features to distinguish homogenous and cohesive units; and functional regions are city-oriented spatial systems defined by the relationships (e.g., labor markets) between the city (central place) and its hinterland [23] [22] [24] [25]. Although formal regions emphasize patterns and the relationships among patterns, functional regions accentuate connections among places and spatial interactions.

Different types of regions have emerged in different academic disciplines for different purposes. Economists, urban planners, and policy makers often consider regions to be city-regions or polycentric urban regions. Landscape ecologists consider regions to be "urban regions", which include socioeconomic and environmental elements that can be integrated within a framework of regional landscape planning.

\subsection{City-Regions, Megaregions, and Polycentric Urban Regions}

Patrick Geddes first described the concept of a city-region in 1915 in his classic work Cities in Evolution [1], in which he argued that in certain regions of the world, individual cities and towns had become coagulated into conurbations (see also Hall, 2009 [12]). In 1961, the French geographer Jean Gottman [26] first defined the term megalopolis, which referred to a conglomeration of cities linked through a dense transportation network in the coastal northeast of the United States from Boston to Washington (see also Pannell \& Loughlin, 2015 [27]).

Although a universally congruent definition of the city-region is not available, the term may be used to define a portion of land that includes a densely urba- 
nized core and the surrounding hinterland. The relationships between the core and its hinterland are typically tied together by numerous functional flows [14] [15]. The interactions between an urban core and its hinterland form the essence of the city-region, and the flows include people, goods, services, capital, assets, pollution, resources, knowledge, and social norms [13].

The urban core is occasionally substituted by multiple cores, which transform the city-region into a polycentric urban region [15] or a mega-city region [12]. The reasons why a region may have multiple cores instead of one core include its history, physiographical conditions, or socioeconomic forces. These multiple cores are usually connected in a network of urban systems through transportation and information infrastructures that support and facilitate interactions among the cores and between the cores and the hinterlands.The process of "concentrated deconcentration" occurs within the mega-city region boundary. Globalization and the shift to an advanced service economy (or informationalization) are the underlying mechanisms for the development of emerging mega-city regions [11] [28].

The city-region concept typically describes the issues concerning a single urban core and its surrounding hinterlands, and the relationships between them. However, modern regional landscapes and geographic systems often transform into systems with multiple urban cores interrelated with their complex hinterlands. These areas can be deemed mega regions or polycentric urban regions. A megaregion can be depicted as networks of metropolitan areas hundreds of kilometers wide that share ecosystems and natural environments, linked by various infrastructures, and sharing economic markets and cultural affinities [29] [30] [31] [32]. Examples include America's Great Lakes region, the Northeast region, and Southern California; the Yangtze River Delta region of China; etc.

Polycentric urban regions (or urban system networks) may be treated as one type of city-region, and they are often depicted as collections of distinct cities that are located in close proximity and well connected through socioeconomic forces and infrastructures [14] [33] [34]. This concept is another expression of Hall's POLYNET (2006) [11]. Examples of POLYNETs include the Randstad in the Netherlands, the Flemish Diamond area in Belgium, the Kansai area (Kyoto-Osaka-Kobe area) in Japan, and the San Francisco Bay area in the United States. In fact, these two concepts, megaregion and polycentric urban region, characterize the regional landscapes on different scales. While the former refers to larger areas, often more than $100,000 \mathrm{~km}^{2}$, the latter refers to smaller areas.

\subsection{Landscape Ecology Perspective: "Urban Region"}

Richard T. T. Forman defined the seminal landscape ecology concept of the "urban region" in 2008, which was considered a breakthrough in landscape ecology theory. An urban region is an area of active interactions between a city and its surrounding hinterland. The outer boundary of an urban region is de- 
termined by a drop in the rate of flows and movements as one proceeds outward from the city [5]. Typically, the "city" is a large metropolis, although the standard definition of a city includes cities that are much smaller.

Although the range of an urban region is usually determined by local conditions for the specific area, the radius of an urban region is normally $100-150$ $\mathrm{km}$. Often, the attributes that determine the outer boundary are physiographic features (e.g., mountain ranges, water bodies, and land-cover changes), major administrative borders, other nearby cities, or one-day recreation sites.

The physical structure of an urban region can basically be divided into two portions: the metropolitan area and the urban-region ring (Figure 1). The metropolitan area, which is a conspicuous object in satellite images, is a nearly continuously built-up area of the city and the adjoining suburbs. The urban-region ring refers to the area outside the metropolitan area, inside the urban-region boundary, and is a mosaic of greenspaces interwoven with built systems. Villages, towns, satellite cities, and infrastructure such as highways, railroads, powerlines, airports, and harbors are all types of built systems. Greenspaces are unbuilt areas in an urban region and include numerous types of unbuilt lands not only within the urban-region ring but also within the metropolitan area. Greenspaces include playing fields, wetlands, forests, nature reserves, market-gardening areas, farmlands, and river corridors. In addition, barren lands such as landslide-induced barren slopes, sand dunes, and beaches may also be inside the urban-region ring.

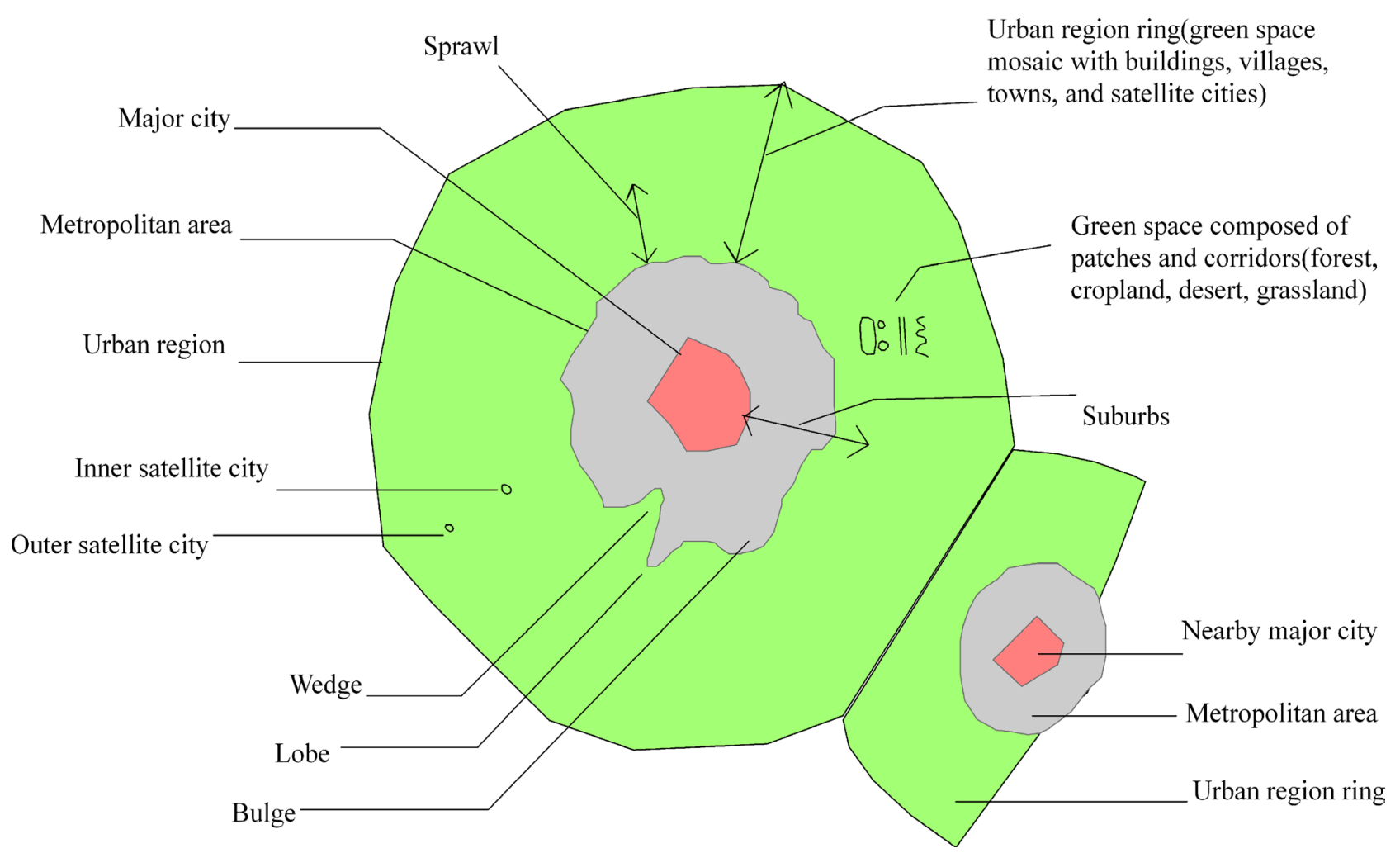

Figure 1. Concepts and terms for urban region. Source: Forman (2008, p. 6). 


\section{Geographic Conditions and the History of the GPRD}

The GPRD study area is a relatively unique and special geographic area that is located on the northwestern edge of the Pacific Ocean in the southern coastal area of China. The geographic range is between $21.6 \mathrm{~N}$ and $24 \mathrm{~N}$ latitude and $112 \mathrm{E}$ and $115.4 \mathrm{E}$ longitude, and the area is $44,891.2 \mathrm{~km}^{2}$ (Figure 2). The distances between the developed regions are large enough to identify the GPRD as a geographically isolated area that is at least $600 \mathrm{~km}$ from Nanning to the west, Changsha to the north, and Xiamen to the east. Administratively, this area includes 11 prefecture-level and upper units: two province-level Special Administration Regions (SARs) (the Hong Kong and Macau SARs), two sub-provincial cities (Guangzhou and Shenzhen), and seven prefecture cities (Zhuhai, Huizhou, Dongguan, Zhongshan, Jiangmen, Foshan, and part of Zhaoqing) (Government of the People's Republic of China).

As an interwoven and densely crisscrossed waterway system along the central coast of south China, the Pearl River flows across flat lands from the western, northern, and eastern mountains, along with its tributaries and distributaries, into the South China Sea. It is said that the Pearl River Delta (PRD) was initially formed approximately 6000 years ago. For thousands of years, the Pearl River system has transported soils and other sediments from the surrounding mountain areas to the central low lands and the sea, and this sedimentation eventually formed the PRD. The delta itself is a mosaic of low lands (terraces and plains), water bodies (ponds and lakes), and small hills (ranging from dozens to hundreds of meters in height). The topographic distribution within the GPRD is similar to a large basin. Surrounding the PRD are mountains to the west, north, and east that have hill tops and mountain ridges ranging from several hundred to more than one thousand meters above sea level, which give the delta the appearance of a large mouth opening to the South China Sea.

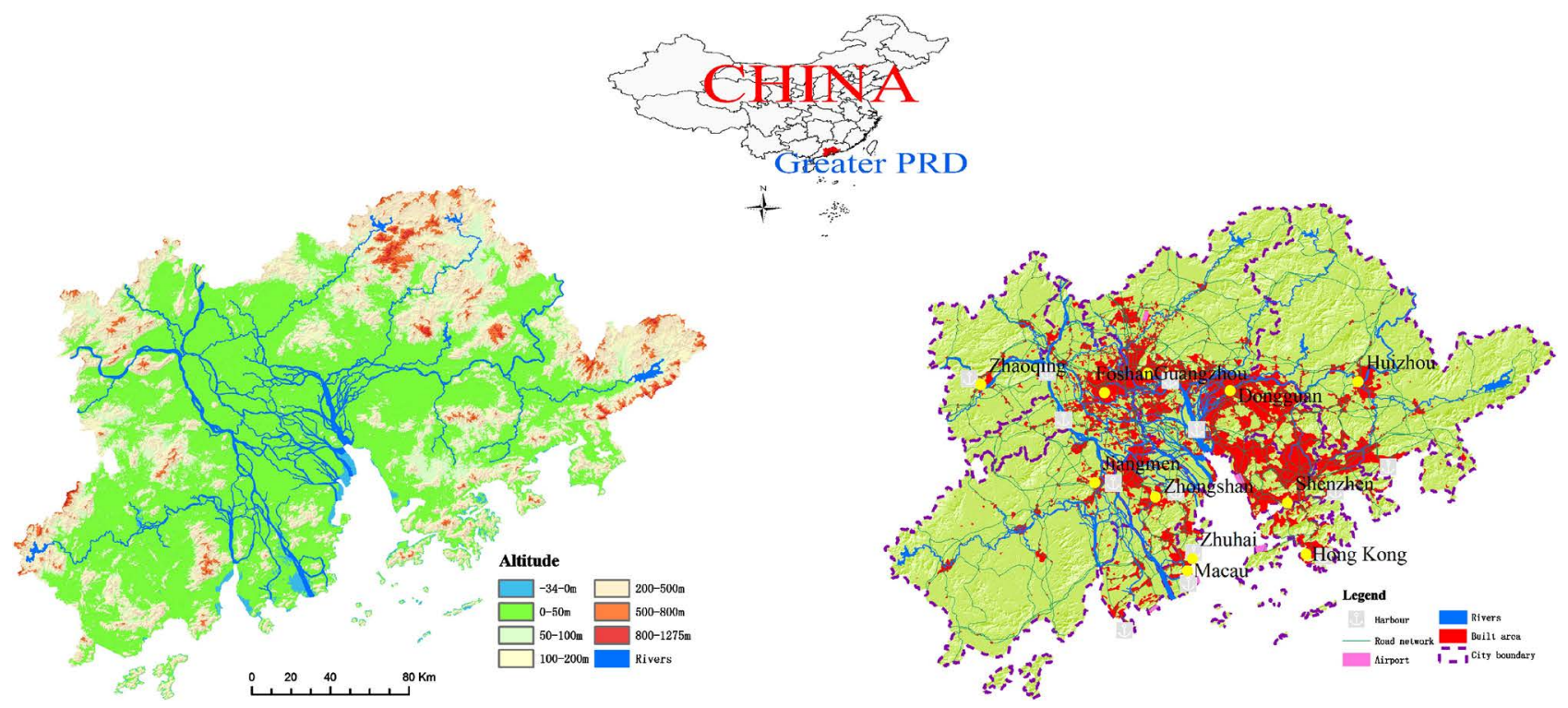

Figure 2. Location and geographic context of the greater Pearl River Delta. 
This region has a subtropical climate with average annual temperatures between $21^{\circ} \mathrm{C}$ and $23^{\circ} \mathrm{C}$ and average precipitation from 1600 to $2600 \mathrm{~mm}$. The typical East Asian monsoonal circulation produces $80 \%$ of the rainfall from April to September. The dominant winds are from the northeast in the winter and from the southwest and southeast in summer, and typhoons usually occur with the summer monsoons. This warm and humid climate favors the growth of vegetation. For at least 3000 years, subtropical agriculture has flourished in this region, and the population has consistently increased despite occasional drops due to wars or natural disasters. Gradually, towns and cities emerged and have served as trading centers, industrial production sites, administrative locations, military fortresses, and transportation hubs.

Approximately 2000 years ago (Qin Dynasty), Guangzhou established itself as a significant city in south China and developed prominence as a commercial, political, cultural, and military center. The famous Maritime Silk Road began in Guangzhou in 200 A.D. Guangzhou is the only harbor in world's navigation history that has lasted for two thousand years. At the beginning of the $19^{\text {th }}$ century, Guangzhou had more than 500,000 residents and was one of the 10 largest metropolises in the world. Foshan, a city near Guangzhou, was also a historical commercial and cultural center during the Tang and Song Dynasties (from 600 A.D. to 1200 A.D.). During the Ming and Qing Dynasties (from 1400 to 1900), Foshan became one of the four most famous towns in China.

In 1553, Macau, a small fishing village, became a Portuguese colony and an important outer harbor for the Port of Guangzhou, and 150 years later, it became an international commercial metropolis. In 1842, Hong Kong was transferred by the Qing Dynasty to the United Kingdom as a British colony, and it quickly developed into an important world city that has served as a global trade, transport, finance, information, and command center for at least 100 years. Presently, Hong Kong and Guangzhou act as two cores of a bi-polar spatial socioeconomic structure [35].

After the establishment of the People's Republic of China in 1949, there were four decades of a centrally planned Soviet-style economic and political culture in China. However, China adopted a reform and opening-up policy in 1978, and for the four decades from 1980 to the present, considerable foreign investments and the adoption of modern western technologies have led to the rapid development of the GPRD, especially in the economic dimension. Special Economic Zones-Shenzhen and Zhuhai-were established in 1980. Gradually, the entire mainland PRD was opened to the global market. The GPRD became known as a "factory for the world", and Hong Kong and Macau began serving as command and control centers as well as centers for financial and investment resources, although Macau played a limited role because of its small size. In addition to its economic functions, Guangzhou continues to maintain its administration and cultural status. In 2014, the total gross domestic product (GDP) of the entire GPRD was $1,266,725$ million US dollars, which accounted for $12.23 \%$ of the 
GDP of China, and the total population exceeded 80 million [36] [37].

\section{Methodology}

\subsection{Bridging Nature Conservation and Urban Development}

Urban planning often highlights the quality of people's lives, whereas conservation planning stresses the natural systems on which people depend. However, a new strategic approach is required that syncretizes the needs and demands of people and nature to create a new whole [5]. Further, on a regional scale, a bridge to coordinate ecological conservation systems and human societal development is needed, and the urban region concept maybe a feasible framework.

Nature conservation and urban development are different but complementary dimensions when arranging regional land uses. On its own, each approach is only partial, but integrating the two aspects permits a powerful synthesis and, as such, represents an improvement on the previous analyses that typically reference only one of the two approaches. Here, we propose landscape ecology's "urban region" concept as a regional land use strategy. The key is that the urban region concept integrates human development and nature conservation within a defined area, and its objective is to design a regional land-mosaic scenario for natural systems and human populations based on a patch-corridor-matrix model under the urban region concept.

Geographically identical regions consisting of central metropolitan areas surrounded by related hinterlands are found worldwide. These regions are regarded as "urban regions" from a landscape ecology perspective or "city-regions" from a socioeconomic perspective. As delineated by Forman, these urban regions are landscapes with two types of structures: built-up areas of metropolitan areas that serve as dominant central locations and surrounding urban-region rings that act as hinterlands of the central metropolitan areas. The urban-region rings are composed of greenspaces and embedded built-up lands. From a landscape ecology perspective, to address regional landscape planning issues, these regions can be treated as objects of systematic complexes, and by employing landscape ecology principles, a regional landscape/land-use spatial arrangement framework can be developed.

The ecological conservation areas and agricultural lands of the natural or semi-natural scopes of the urban-region ring are the fundamental elements on which this urban region conceptualization should focus, while the central metropolitan area serves as the centroid and starting point for urban land uses. The following sections outline a scheme to promote regional land-use spatial arrangements and solutions based on ENs for nature protection and CPT for urban development. The framework uses the GPRD as the empirical study area. Emphasis is placed on suggestions from two opposing perspectives: urbanization land use and strictly ecological/environmental conservation areas. The remaining lands within the study area are assumed to be agricultural lands or other areas. 


\subsection{Embedding Networks into the Urban-Region Framework}

As pointed out in the previous section, on a regional scale, nature conservation and urban development can be integrated within an urban-region framework from the landscape ecology perspective. However, the objectives of nature conservation can be materialized through the EN approach. Similarly, CPT serves as an effective approach to arranging urban development land use. This will enhance and improve the Formanian urban-region conceptualization.

An EN may be described as a system of nature reserves (core areas) and their interconnections (corridors) and buffer zones that increase the coherence of a fragmented natural system to support ecological processes or landscape functions. The main roles of the EN are providing species habitats and maintaining and improving functional ecological connectivity, except other functionalities [7] [9] [10].

Surely, on a regional scale, this EN lies within the urban-region ring, interwoven with agricultural landscapes and other lands. For the GPRD, this EN will be designed and proposed based on landscape ecology theory and geographic spatial analysis techniques, serving as the fundamental components of the regional landscape planning vision.

On the other side, an urban development scheme can be conceived based on CPT. Classical CPT provides a methodology to explain and arrange the number, location, size, and functional content of settlements within a region. By defining a compound index of Central Place Importance (CPI), this study attempts to arrange the urbanization strategy within the study area using $\mathrm{CPT}$ and combining it with the "satellite-cities model" proposed by Forman [5].

Due to the modern complex transportation and information infrastructures, as well as the complementarities and cooperation among urban centers, the urban centers themselves formulate a regional urban network at the opposite side of the EN.

The ultimate objective of this scheme is to embed urbanization areas (the urban network) based on CPT, the patches, into the natural and semi-natural landscapes (the EN and agricultural lands), the matrix. This strategy eventually achieves the goal of protecting the natural system while meeting urban development demands. In Section 4.5 and Section 4.7, respectively, this strategy will be realized within the GPRD study area.

\subsection{GPRD Megaregion as a Polycentric Urban Region}

In addition to the rapid socioeconomic reform and development observed in China since 1978, regional integration policies have been enacted and urbanization has occurred, especially within the GPRD, which is emerging as a global mega-city region.

Peter Hall defined a mega-city region (megaregion) as "a series of anything between twenty and fifty cities and towns, physically separate but functionally networked, clustered around one or more larger central cities, and drawing eco- 
nomic strength from a new functional division of labor" [12]. The GPRD can be considered a mega-city region. In 2010, it included 16 metropolitan areas with a population of over 500,000 permanent residents, three of which (Hong Kong, Guangzhou, and Shenzhen) had populations greater than 5,000,000. The economic functions of this region are distributed and interwoven in a complex fashion across the delta. Hong Kong, as a global city, serves as a command and control center and dominates the upper-value industries; Guangzhou serves as a center for administrative and other services; Macau serves as a tourism city; Shenzhen is dominant in high-tech industries; and the other cities and towns of the delta are responsible for routine manufacturing and service functions. By definition, the entire GPRD is highly centralized on a global scale.

The GPRD mega-city region is typically a polycentric urban region because this region includes several large metropolises surrounded by dozens of cities, which in turn, are neighbored by small towns and all of these locales are connected through densely distributed transportation routes.

\subsection{The Guangzhou Urban Region and the Hong Kong Urban Region}

The city-region concept addresses the GPRD from asocioeconomic perspective. However, the approach defined here considers this study area from an opposite but related perspective-the "urban region" concept from the landscape ecology perspective. Within the delta, Guangzhou and Hong Kong are two development poles and historically dominant cities located in the inland northwest and the coastal southeast of the PRD, respectively. Furthermore, Guangzhou and Hong Kong are two cores of their respective city-regions. The influence of Macau is limited because of its small size.

Thus, the GPRD mega-city region can be divided into two urban regions: Guangzhou in the northwest and Hong Kong in the southeast (Figure 3). Although the lands they cover superimpose each other, the objective of this study is to analyze the entire region from their respective core areas (the two big metropolises) and treat the landscapes within the urban region rings accordingly.

As mentioned in previous sections, an urban region consists of two portions: the inner metropolitan core area and the outer urban-region ring. Within the GPRD, the two cores are the Guangzhou metropolis and the Hong Kong metropolis, and each metropolis has an urban region ring. Although the boundaries of urban regions are often defined as $100 \mathrm{~km}$ [5] or $150 \mathrm{~km}$ [11] [12], the local geographic conditions are complicated and place-specific. The straight distance between the downtowns of Guangzhou and Hong Kong is $130 \mathrm{~km}$. The farthest radial distances from the two cores, Guangzhou and Hong Kong Island, to the remote edge settlements do not exceed $210 \mathrm{~km}$, and almost all of the small towns are located within a radius of $200 \mathrm{~km}$ from Hong Kong Island and Guangzhou metropolis. Thus, $200 \mathrm{~km}$ was selected as the outer boundary for both the Hong Kong and Guangzhou urban regions. 


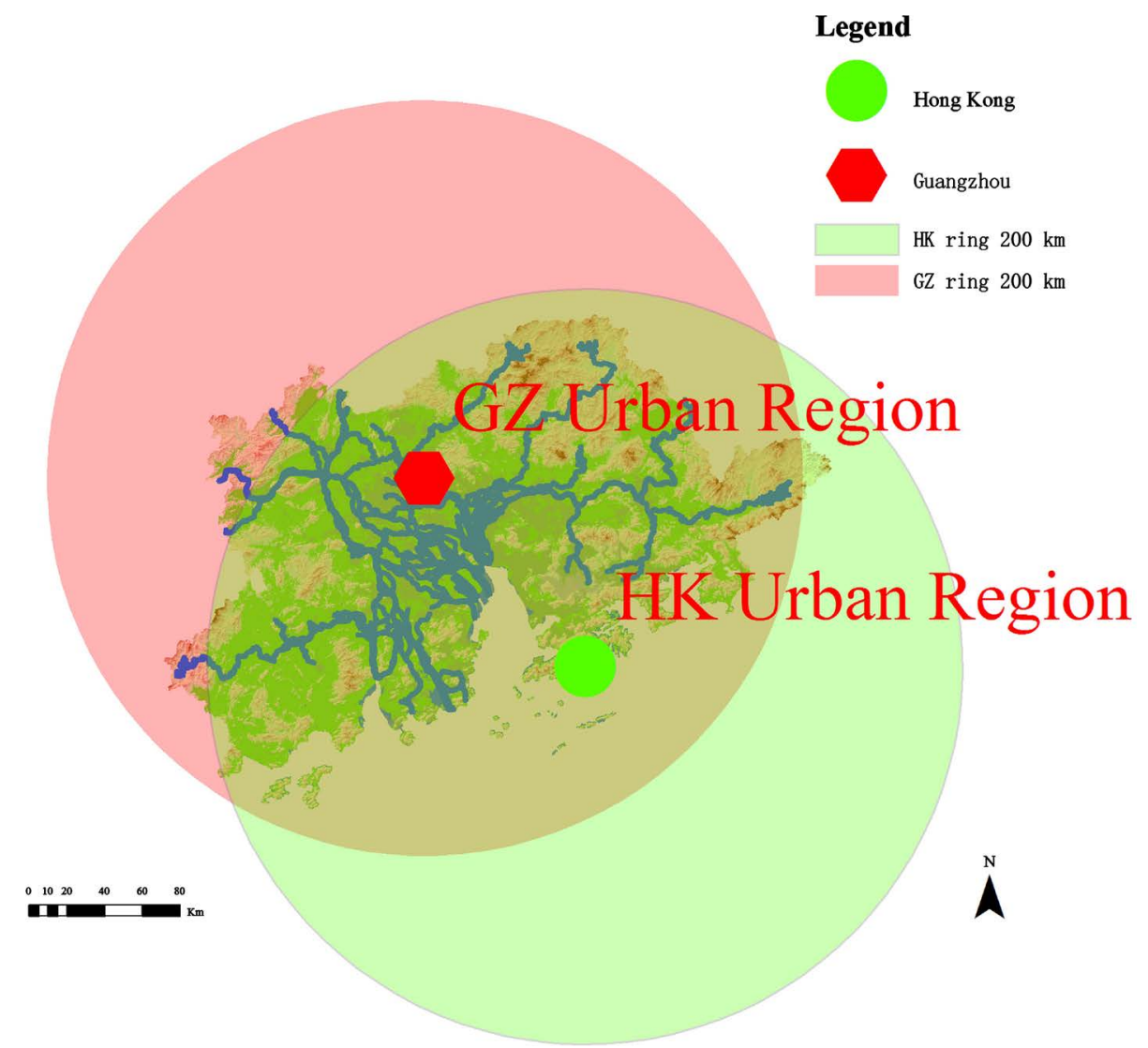

Figure 3. Two urban regions: Hong Kong urban region and Guangzhou urban region.

\subsection{ENs (Ecological Networks)}

Different researchers discuss and design ENs from different perspectives because they come from different professional backgrounds. It is widely accepted that there are two schools in EN design around the world: the landscape approach and the species-specific approach [6] [8] [38]. Additionally, Théau et al. [39] asserted that the landscape ecology approach is one of the best ways to design an EN.

The ecological protection solutions were addressed through a broadened regional EN system that enhances landscape connectivity facilitating natural processes, including movements of species as well as people. Such networks are the fundamental backbone of nature protection primarily focusing on the "urban-region rings", which Forman termed "emerald networks" [5] [40].

This regional EN was established through a landscape ecology approach employing GIS spatial analysis to enhance and restore landscape connectivity. The formulated EN was established via the following process. After collecting and preparing data from various sources, an ArcGIS overlay algorithm was used to identify the core areas and then, a least-cost path algorithm in GIS was employed to delineate the ecological corridors, thus creating a regional EN. Afterwards, the regional EN was extended to include riparian connectivity protection areas and stepping stones. Finally, an extended regional EN emerged. 


\subsubsection{Data Preparation}

Data were obtained from various sources and include data related to land cover, vegetation density, topography, human population density, road networks, and settlement locations. All of the data were preprocessed and normalized. Then, projections of all the data layers were converted to the coordinate system of the UTM Zone 50N, WGS 1984.

\subsubsection{Core Area Identification}

Core areas were identified using the ArcGIS overlay analysis module by integrating seven data layers: land cover, vegetation density, human population density, road density, distance to settlement, distance to road, and distance to river. This process includes formatting, normalizing, and reclassifying data; calculating total core area value; determining the thresholds of the core area value that is included; and determining the minimum size of the core area. Eventually, 59 core areas were designed.

\subsubsection{Determining Core Area Pairs to Be Connected}

The edge-to-edge instead of centroid-to-centroid principle was used to select core area pairs to be connected. By referring to Landsat images and the topology of the patches, the locations of source and destination pixels to situate the "sticks" to link the core areas were determined for the purpose of establishing a least-cost path function or to locate road fragmentation crossings. The stick is a place holder representing connections between two core areas. In the end, 45 sticks were designed to connect 46 core areas.

\subsubsection{Cost Surface Calculation}

A general cost surface calculation for ecological movement within the study area was generated. The cost surface represents the per-pixel cost of movement across the landscape, indicating how difficult it is for organisms or ecological processes to move through the landscape. Factors contributing to the total value of the cost surface include land cover, vegetation density, human population density, road density, elevation, and slope.

\subsubsection{Delineating Ecological Corridors}

The least-cost path algorithm was used to design ecological corridors. This computes the minimum cumulative cost.The primary input to a least-cost model is the above-referenced cost surface calculation. Forty-five least-cost paths were determined based on the above-referenced sticks. Then, the widths of the corridors were defined, resulting in 45 ecological corridors. In addition, road fragmentation crossings were worked out where core areas were only segmented by linear transportations routes.

\subsubsection{Extending the Defined ENs}

Vegetation along major rivers is an important component in nature protection strategies. The study area holds five major river channels. These rivers and their associated tributaries (a total length of $1300 \mathrm{~km}$ ) were designed as riparian 
connectivity protection areas with a buffer of $2 \mathrm{~km}$ on each side of the water channel. This was addressed by simply including the water routes and designing the widths of adjoining buffers. Stepping stones are small natural vegetation patches facilitating species movements. Within the PRD, there are dozens of these patches. These were designed as stepping stones adding to the whole EN system.

\subsection{Agricultural Land Uses}

According to the land-cover classification extracted from Landsat OLI images in 2013 , in the $44,891.2 \mathrm{~km}^{2}$ study area, a built-up area of $7472.35 \mathrm{~km}^{2}$ covered one sixth of the GPRD. Because the formulated broadened regional EN accounts for $48 \%$ of the study area, the remaining agricultural landscapes (including inland water surface but excluding certain barren lands) occupy $15,905 \mathrm{~km}^{2}$, thus constituting one third of the region (Figure 4).

This one-third area accounts for multiple land uses of three general types: pond-dike lands, orchards, and croplands. The pond-dike lands are mainly distributed across the western portion of the PRD plains along the Xi River and Bei River channels; orchards are dispersed within the delta but are relatively

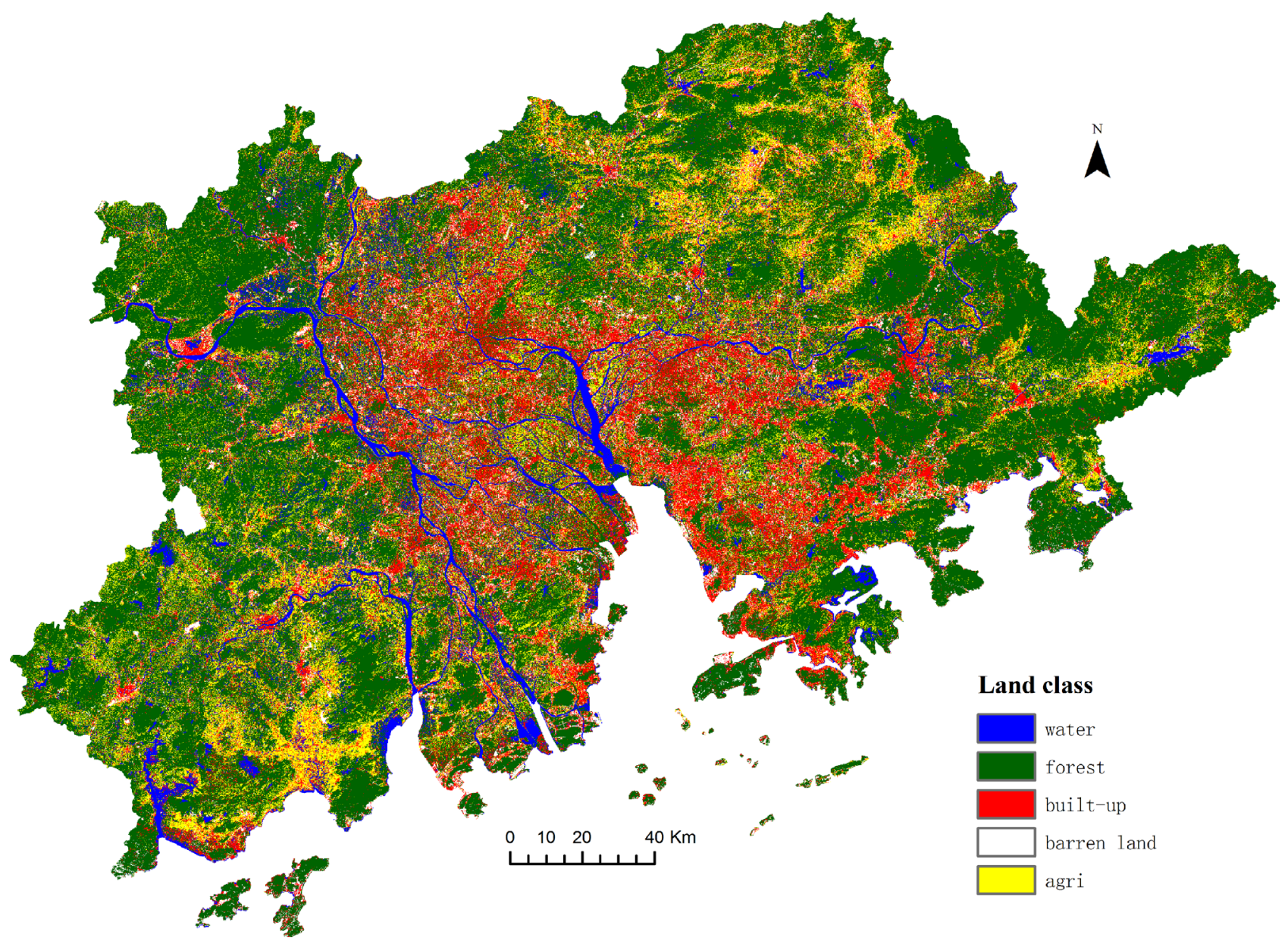

Figure 4. The Greater PRD land cover classification 2013. 
concentrated at the mouths of the Bei River, Pearl River, and Dong River and on the hill slopes of the western portion of the east PRD and the river valleys near Conghua City, Zengcheng City, and Huidong City; and croplands (including paddy fields, dry lands, and vegetable plots) are primarily distributed along river valleys and terraces within the peripheral mountainous areas (Figure 5).

One important agricultural characteristic of this region is the diversity of agricultural landscape types, which primarily involve pond-dike farming, market gardening, orchard farming, and grain farming. This diversity should be maintained and enhanced because manifold landscape types suggest a diversity of food products, farmland species, and flexibility for the future [5]. Encouraging crop diversity and different types of cropland landscapes should be a significant agricultural land-use strategy in the GPRD.

In addition, the GPRD is an open economy. With a population of over 80 million living on approximately $16,000 \mathrm{~km}^{2}$ of available farmland, a considerable amount of the required food resources is generated from areas outside of the region. Moreover, the majority of farmlands in this region do not provide grain products and meat for the urban populations and supply only vegetables, fruits,

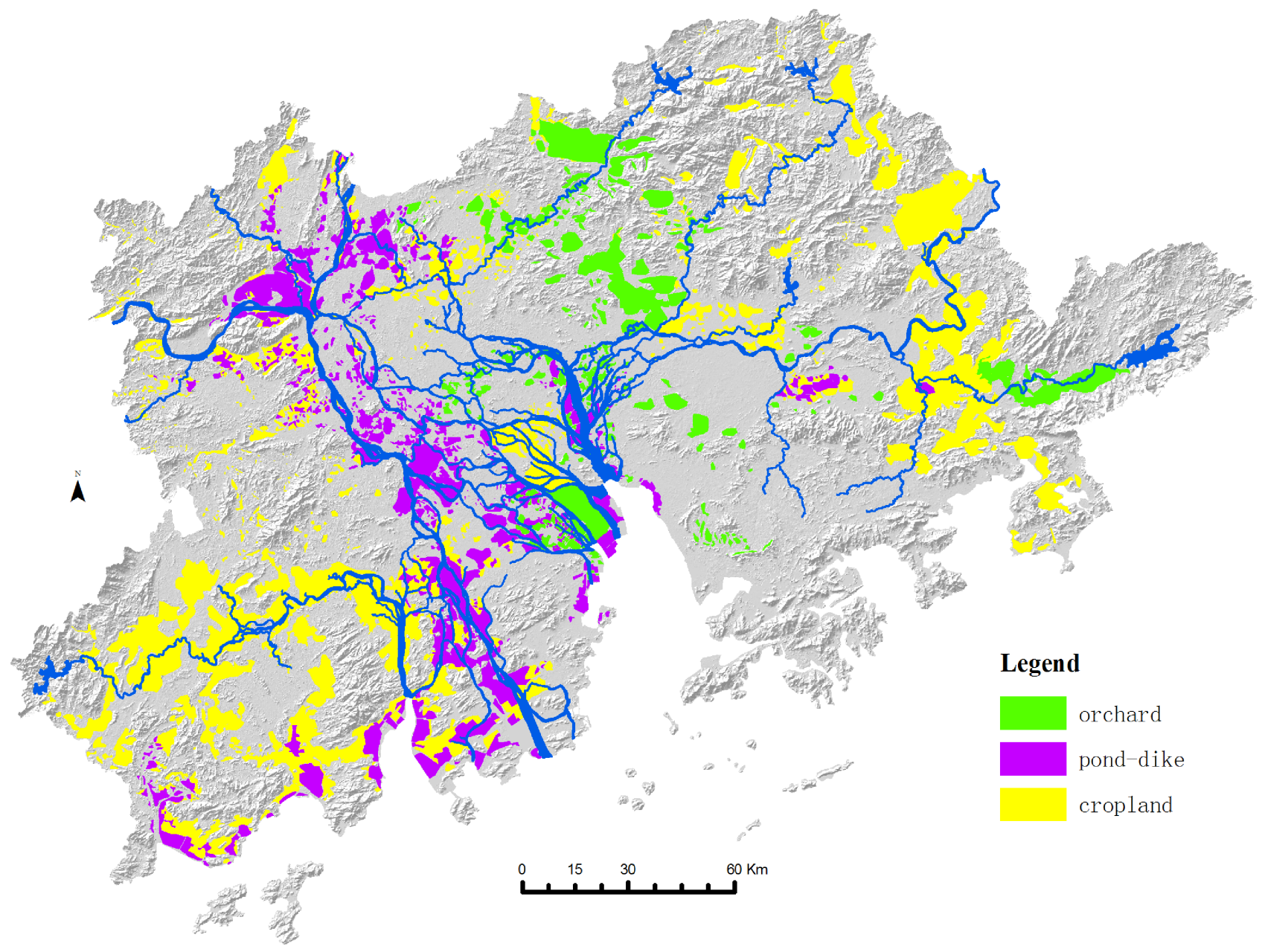

Figure 5. Distribution of the three types of farm land within the study area. 
and aquatic products. Thus, the development of agricultural land use should focus on market gardening and high-productivity rice planting instead of traditional grain farming.

However, the remaining agricultural lands must be strictly protected, especially the prime farmlands, and urban development should use barren lands, low-value farmlands, and low ecological value lands. Specific agriculture development policies are beyond the scope of this paper. The objective of this research is to maintain the distribution and protection of current farming land uses as a component of the regional landscape planning strategy, which emphasizes ecological conservation and urban land use. In addition, agricultural landscapes serve as a buffer between urban development and nature protection.

\subsection{Applying CPT to Improve Urban Systems}

The preceding discussion showed that regional EN and agricultural land uses are fundamental and indispensable components of the GPRD mega-city regional landscape planning vision. Here, a regional urban development strategy based on classical CPT and the urban region concept will be addressed.

\subsubsection{Rationale behind Using the CPT}

$\mathrm{CPT}$ is an old and fully developed settlement location theory. Despite various criticisms and its inherent deficiencies, there seems to be signs of its resuscitation. Mulligan and collaborators believed that an important value of CPT is that it can integrate a number of key concepts in regional science, such as consumer choice, firm agglomeration, and functional hierarchy. Additionally, they stated that CPT indicates how human processes are embedded in space or mediated by location and has practical implications for policy, especially urban and regional planning. CPT has the ability to describe why, how, where, and when city systems materialize on the economic landscape. CPT describes the general framework of the urban spatial structure and has applications for the siting of centralized facilities and the planning of infrastructure for public goods and services. They also concluded that CPT is ready for reemergence and should be viewed as complementing rather than competing with new theories such as new economic geography [19].

Parr [20] suggested that CPT "provides a foundation upon which other facets of the urban system could be superimposed". Thus, an overall urban system including the CPT component and specialized-function activities (other than the CPT component) can be envisioned; that means it is possible to build a comprehensive urban system scheme that integrates traditional CPT with the new urban network theory.

The importance of traditional central place locations remains [11] despite changes introduced by economic globalization and informationalization. For certain activities, an ideal geographic location must be selected. Spatiotemporal factors are fundamental determinants for socioeconomic actions and these affect 
various complex geographic conditions. In addition, common sense indicates that time and resources are required to identify suitable meeting places for face-to-face interactions, whereas daily actions primarily take place locally. Thus, geographic location represents the ultimate constraint for the movement of matter (materials, people, information, etc.), even if the information is transferred electronically.

With the development of emerging regional polycentric urban structures, the redistribution of different urban functions and specializations is increasingly important. This has shifted the relevant focus to the entire region instead of to a single city. A concept that can address these changes is required and CPT appears to be a good choice. The Christallerian hierarchical arrangement of urban land use and the networked polycentric urban region can be integrated into one single framework, although such a realization may be difficult because of complex constraints. In this study, we first used a comprehensive index (compound CPI) to analyze the distribution and hierarchy of settlements and then, described the network dimensions of the urban system through urban network theory. The compound CPI included not only the traditional central place index but also new socioeconomic elements such as advanced service industries. Furthermore, based on an analysis of the present central place system, an upgraded urban development scheme was proposed through the application of the Christallerian market principle and the transportation principle of CPT.

\subsubsection{Choosing a Suitable Urbanization Model}

Urbanization includes densification and the outward distribution of the built environment. Densification represents increased density and building units within the boundary of the built area and includes infilling greenspaces or constructing high-rise apartment buildings. Because this study focuses on land-use changes and landscape transformations, the emphasis here is on outward urban expansion. Therefore, our goal is to design and arrange the land use in the urban-region ring beyond the metropolis.

Forman [5] designed a study from a landscape ecology perspective by employing 18 landscape degradation attributes that were applied to 38 urban regions worldwide, with a focus on natural systems and their human uses. The 18 attributes (e.g., biodiversity sites, forests, rivers, wetlands, distance to a major highway, and subdivision degree) were applied to four urbanization models (the concentric-rings model, the satellite-cities model, the transportation-corridors model, and the dispersed-sites model) to evaluate the effects of urbanization on the degree of landscape degradation associated with the four alternative spatial models, and a ranking of the effects on both the natural systems and their human uses emerged (Figure 6). The models were ranked as follows, from best to worst, according to the effects of urbanization on landscape degradation: 1) satellite-cities model, 2) concentric-rings model, 3) transportation-corridors model, and 4) dispersed-sites model. Therefore, the best choice for urbanization is a satellite-cities model. However, local conditions may indicate that the 


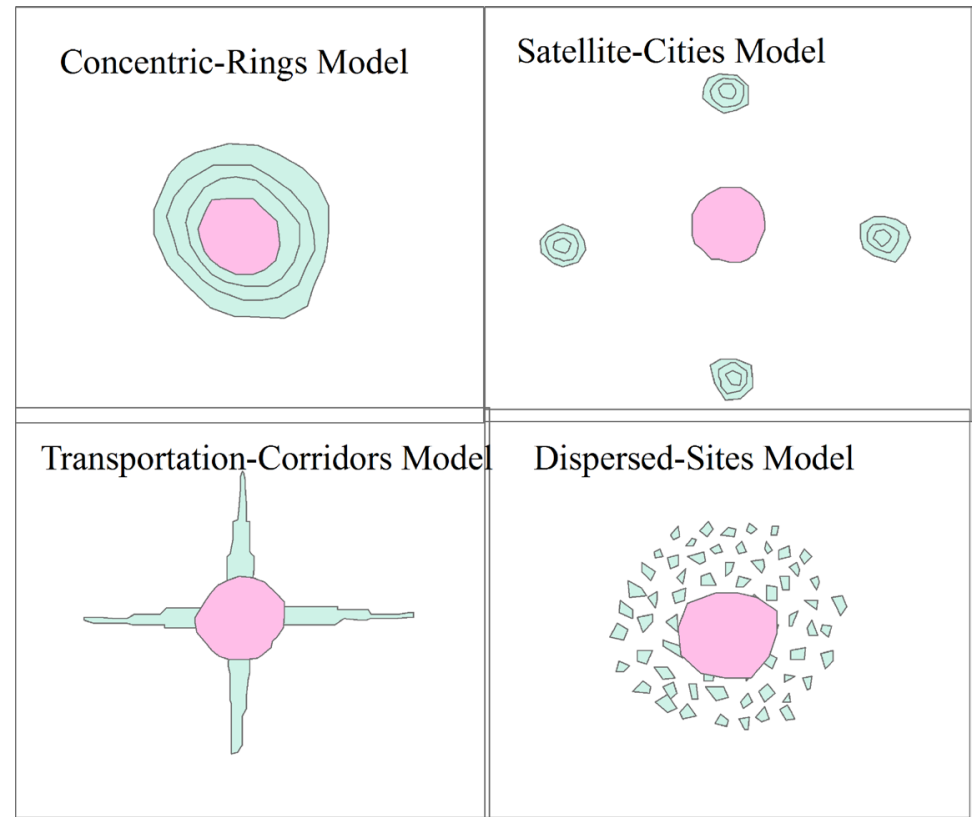

Figure 6. Four major spatial models of urbanization spread. Adapted from Forman 2008.

satellite-cities model should be combined with the concentric-rings model. The following sections focus on the development of a satellite-cities urbanization model and the application of CPT as a method to implement that strategy.

\subsubsection{The Current GPRD Urban System and Central Places}

An urban system has already formed within the GPRD and researchers have referred to it as a mega-city region [11] or city-region [35]. By applying classical $\mathrm{CPT}$, this urban system can be presented as classified groups distributed across the study area.

A compound CPI was employed to represent the relative importance of the settlements. The CPI is an index integrating five elements: population, GDP, political administration location, company headquarters location, and transportation values. It was calculated using the following formula:

$$
\mathrm{CPI}=\mathrm{P}+\mathrm{D}+\mathrm{G}+\mathrm{C}+(\mathrm{A}+\mathrm{S}+\mathrm{R}+\mathrm{H}) / 4
$$

where CPI is the value of the compound CPI index, $\mathrm{P}$ is the total population of the settlement, $D$ is the GDP, G is the value of the government administration location, $\mathrm{C}$ is the value of the company headquarters location, and $\mathrm{A}, \mathrm{S}, \mathrm{R}$, and $\mathrm{H}$ represent values for airports, harbors, railways entering the central place, and highways entering the central place, respectively. Each of the five factors was assigned the same weight. The values of the CPI were ranked, grouped, and classified, and the resulting distribution of the central places (CPs) (towns, cities, and metropolises) is depicted in Figure 7.

\subsubsection{Upgrading the GPRD's Urban System}

Economic growth and landscape/land-use changes are constantly occurring in the GPRD and its urbanization will continue while its landscapes degrade. The 


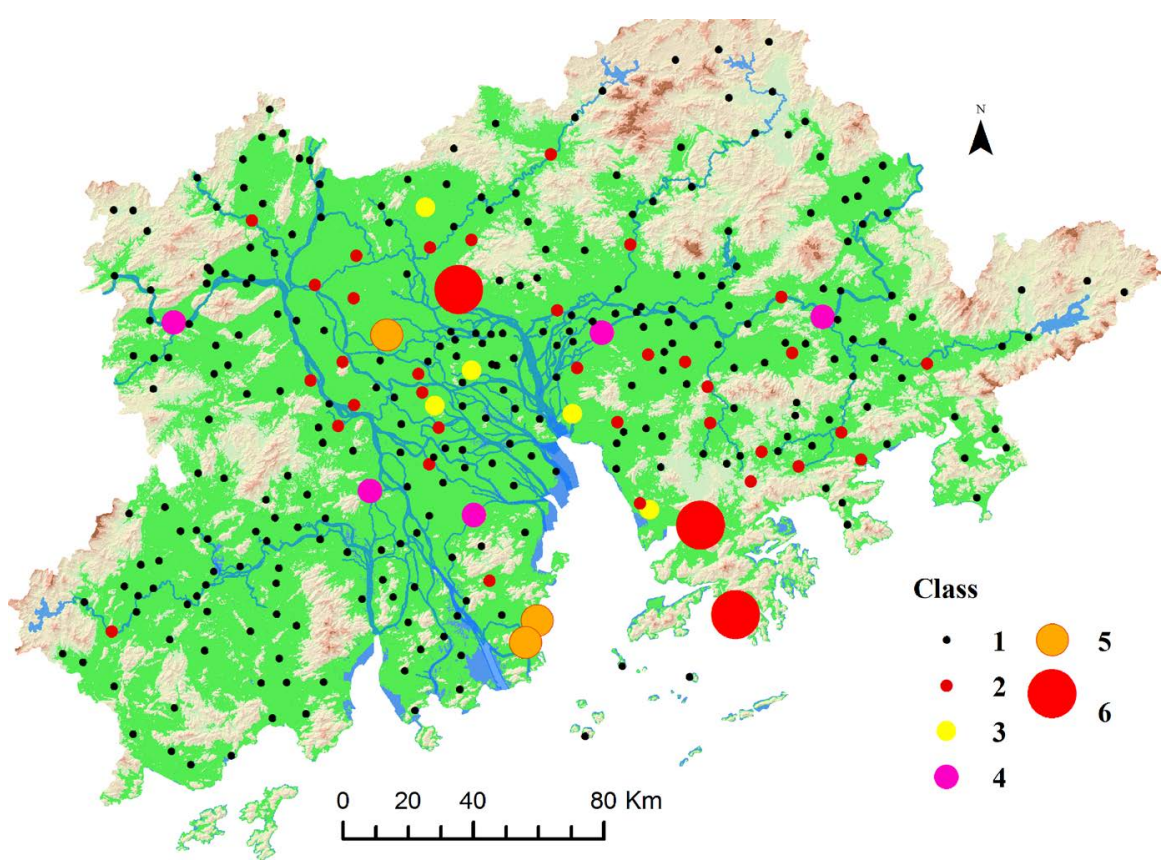

Figure 7. The six level settlements distribution within Greater PRD (2010).

cities and towns are encroaching upon rural areas, and endemic species and protected areas are in danger. Thus, a strategy to guide the urbanization process is necessary. The CPT appears to be a good choice, and it is congruent with Forman's satellite-cities urbanization model.

Using the market principle $(\mathrm{K}=3)$ and transportation principle $(\mathrm{K}=4)$ of Christaller's classical CPT, we review the six classifications of CPs (towns, cities, and metropolises) presented in Figure 7. For the market principle, the lower-class CPs are located at each of the six vertexes of the hexagon hinterland of the upper CP; for the transportation principle, the lower-class CPs are located at each of the mid-points of the six edges of the hexagon hinterland of the upper $\mathrm{CP}$. The locations of the current CPs were framed into networks by applying these two principles to the Hong Kong urban region and Guangzhou urban region (Figure 8).

After reviewing the six classifications of CPs from the upmost class, Class 6, (Hong Kong and Guangzhou) to Class 3, several CPs were found that can be developed and upgraded to one or two upper-class CPs. Thus, certain Class 3 CPs can be developed into Class 4 CPs or Class 5 CPs depending on local conditions. Furthermore, for a location that does not include a Class $3 \mathrm{CP}$ (vertex for market principle, mid-point for transportation principle), a nearby lower-class CP (Class 2 or Class 1 ) can be transformed into a Class 3 , Class 4 , or Class $5 \mathrm{CP}$ for future development.

Because these $\mathrm{CP}$ principles formulate the spatial layout of settlements into hexagons, it is possible to postulate the satellite-cities urbanization model in a six satellite-cities format instead of Forman's four satellites model. However, for local geographic conditions, an upper-class $\mathrm{CP}$ does not require all six lower 

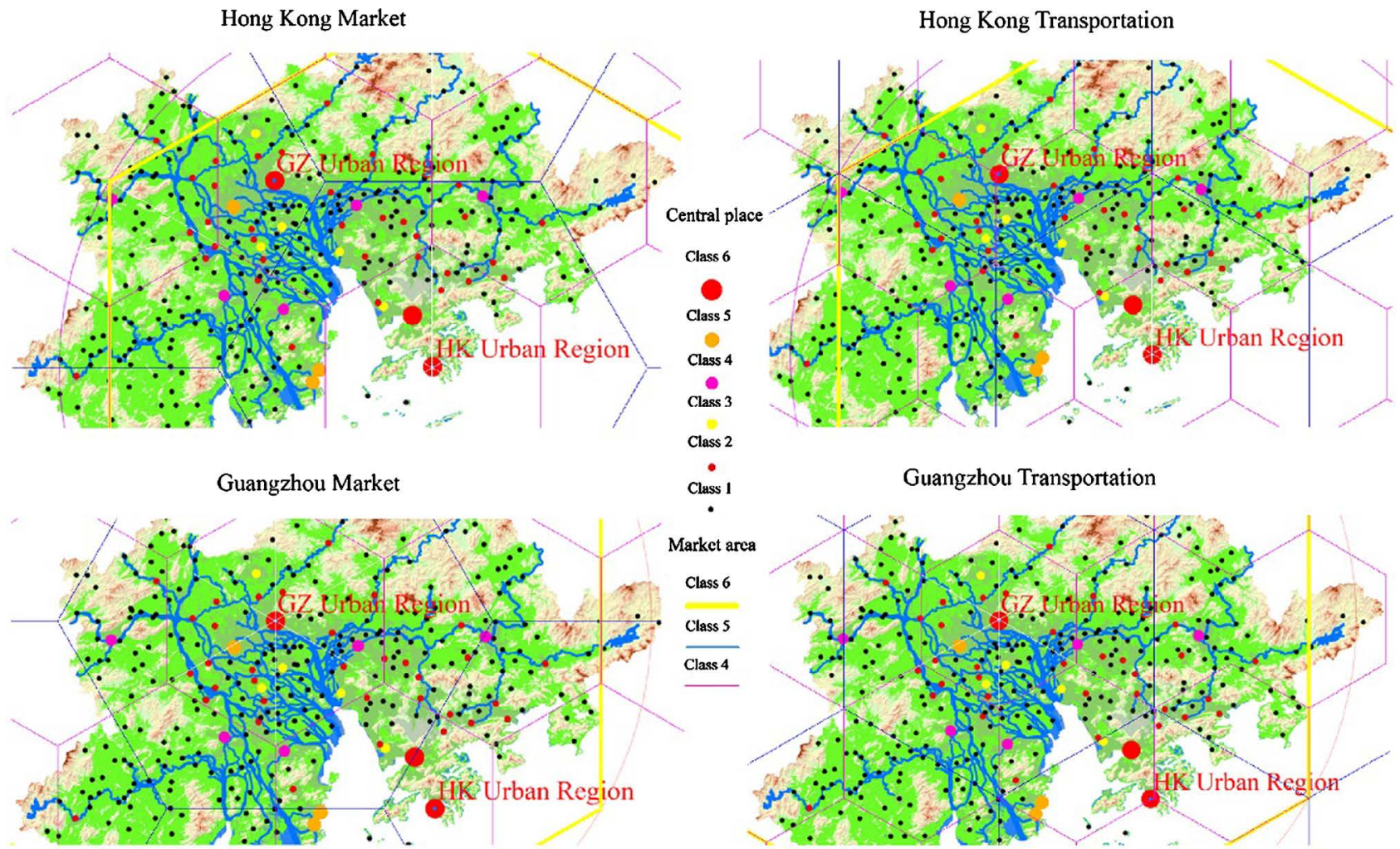

Figure 8. The spatial distribution of central places within Greater PRD in 2010 framed by applying the market principle and transportation principle central place theory, respectively.

CPs. Therefore, certain lower CPs do not have to be considered in relation to the local conditions, especially within the peripheral mountainous areas. Moreover, even within the plains delta, certain planned settlements may deviate from the strictly defined Christallerian vertexes or mid-points because of the realities of these areas. In addition, when a CP is planned, a present town or city should be utilized when possible.

\subsection{The Urban Network Analysis}

An urban network can be described as a nodal region that consists of nodes (cities, towns, firms, etc.), linkages between the nodes (infrastructure, ties, etc.), socioeconomic complementarity relationships, interactions (flows) between the centers, and areas surrounding the nodes (hinterlands). Hierarchical relationships may exist between the urban centers (nodes), while complementarity relationships and spatial interactions between the urban centers must be present, at least to some extent. The most important feature of an urban network is that there are complementarity relationships between the urban centers within the urban network, that is, different urban centers fulfill different and mutually beneficial roles. Another important feature of an urban network is cooperation between different settlements [16] [17] [18].

Complementarity can be depicted through the correspondence analysis technique in SPSS software. Correspondence analysis is a technique that is used to 
analyze the association between the rows and columns of a table or matrix by representing the rows and columns as points in a low-dimensional Euclidean space. Categories with similar distributions are represented as points that are close in space and categories that have very dissimilar distributions are positioned far apart [34]. Total inertia is an important measurement that describes the extent of differentiation in the socioeconomic profiles of a group of urban centers. The centroid represents the average profile. The greater the distances of the category points from the centroid, the higher the inertia. The highest attainable inertia is equal to the dimensionality of the problem (the number of urban centers-1), while the lowest is zero. Another interesting statistic, the complementarity ratio, was defined by Meijers [34]. The complementarity ratio is calculated by normalizing the total inertia. This is accomplished by dividing total inertia by the maximum total inertia possible and multiplying the result by 100 , which yields a value between 0 and 100 .

Within the GPRD, 11 cities and 20 socioeconomic elements from years 2004 and 2010 were analyzed. Using the correspondence analysis tool in SPSS 20, the differentiation of socioeconomic activities between the 11 cities and the total inertia and complementarity ratio of the GPRD were calculated. The total inertia was 0.828 - 0.753 (2004-2010); the complementarity ratio for the GPRD was 8.3 7.5 (2004-2010); the trend from 2004 to 2010 was -9\%, indicating the decreasing complementarity of economic and service activities (Figure 9).

Cooperation within the GPRD has been ongoing and continuous since China adopted the reform and opening-up policy in 1978. Several levels of administrative governments participate in discussing regional development issues in the GPRD

(a)

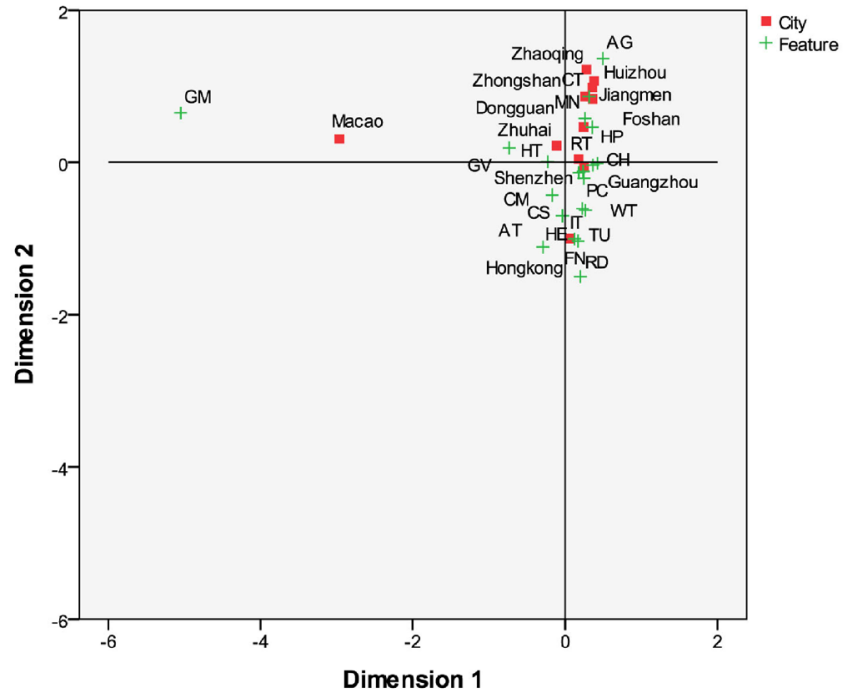

Key to abbreviations:

Agriculture AG;

Manufacture MN;

Hotels HT;

Government GV; Post and communication. PC. Construction CS; Company headquarter $\mathrm{CH}$; $\quad$ Railway transportation RT; Gaming industry GM; Hospitals HP; (b)
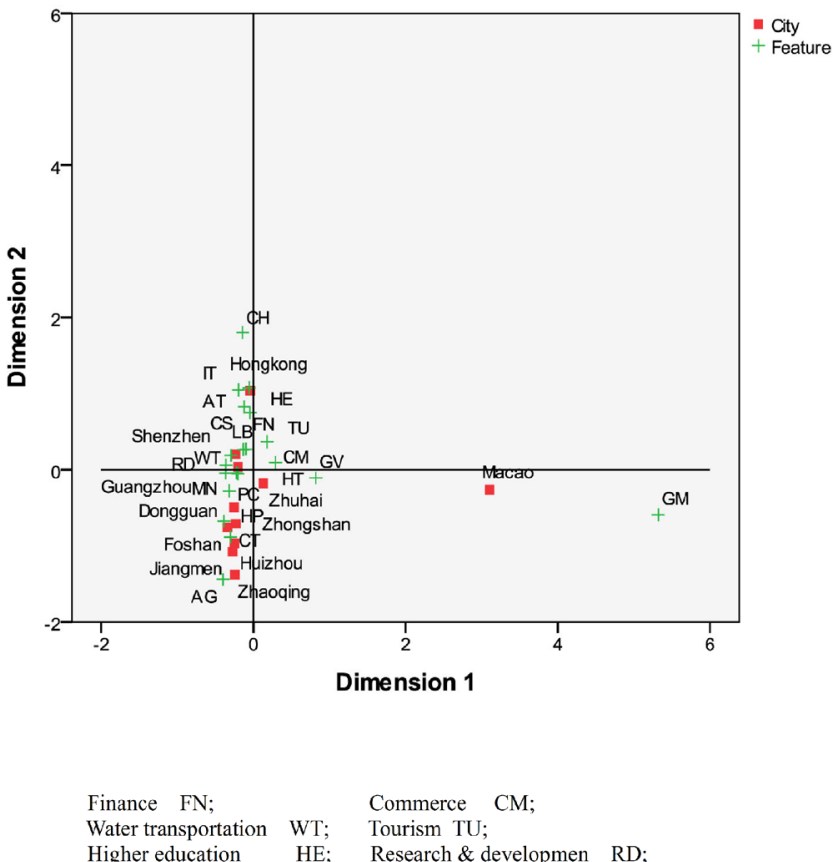

Cinema and theatre $\mathrm{CT}$; Library LB.

Figure 9. Differentiation in the spread of socioeconomic activities over the 11 cities within Greater PRD, 2004 (a) and 2010 (b). 
area, including the Chinese central government, Guangdong province, the SARs, local municipalities, etc. During different periods, various institutions and governments promulgated and implemented plans and policies aimed at strengthening cooperation and integration between the internal PRD cities and the Hong Kong and Macao SARs. Examples include the Pearl River Delta Urban Cluster Cooperative Development Plan (2004-2020) adopted by the Guangdong provincial government in 2005; the Outline of the Plan for the Reform and Development of the Pearl River Delta (2008-2020) released by the National Development and Reform Commission in late 2008; the project to build a bridge linking the eastern and western wings of the PRD known as the Hong Kong-Zhuhai-Macau Bridge (HZMB), etc.

\section{Results}

\subsection{The EN}

Figure 10 shows the extended regional EN map for the entire GPRD. This includes 46 core areas (ranging from 10 to $3000 \mathrm{~km}^{2}$ ) connected by 45 corridors, 11 stepping stones, and 1300-km blue-green corridors. The total area of the extended EN and the stepping stones is $16,995.38 \mathrm{~km}^{2}$ covering $37.86 \%$ of the

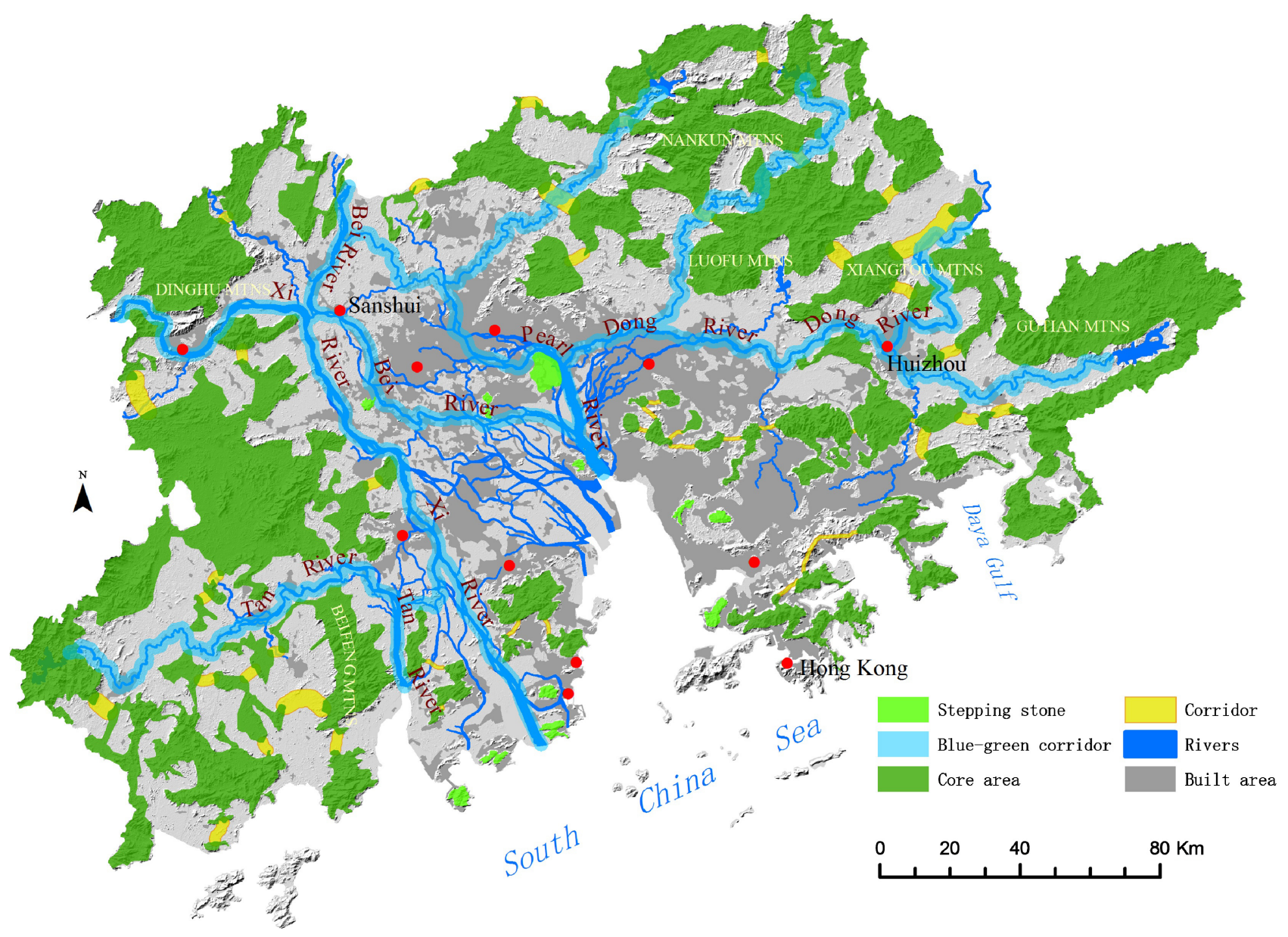

Figure 10. The extended ecological network map. 
entire study area, with core areas at $16,053.26 \mathrm{~km}^{2}(35.76 \%)$, corridors at 704.47 $\mathrm{km}^{2}$ (1.57\%), and stepping stones at $237.65 \mathrm{~km}^{2}$ (0.53\%). However, for the $1300-\mathrm{km}$ blue-green corridors, although they were assigned a $4 \mathrm{~km}$ width, it is unrealistic to determine a digital figure to express the total coverage, as there will be different widths along different river reaches. That is a conceptual vision.

The major roles of this regional extended EN are maintaining and improving landscape connectivity and providing habitats for species, and do not include other functions such as recreation. Furthermore, this regional EN also functions as the foundation and backbone for a regional landscape planning strategy, as other land uses are restricted and guided through this EN.

\subsection{The Urban Network}

As analyzed in Section 4.8 and depicted in Figure 9, complementary relationships between the 11 cities within the study area exist. Additionally, regional cooperation between cities, especially coordination between the two SARs (Hong Kong and Macau) and the Mainland PRD, is playing an important role in regional development and urbanization. Further, a modern and densely distributed transportation system and information infrastructure closely link the settlements. These, in fact, make the GPRD an integrated urban system network and this will continue to be enhanced and improved.

Although it seems difficult to display the complex functional inter-city socioeconomic relationships through a two-dimensional map, exhibiting the distributions of various settlement classes and the related advanced transportation systems on a single map somewhat reveals the facts of the urban network (Figure 11).

\subsection{Upgraded Urbanization Centers}

Based on the rules and methods set forth in Section 4.7, seven of the settlements (CPs) within the study area were designed to be upgraded to urbanization priority locations. Two settlements, Kaiping and Yamen, were upgraded to Class 4. The other five, Huiyang, Tangxia, Nansha, Gaoming, and Dawang, were designed as Class 3 settlements. These seven locations were designated as primary urbanization locations for regional planning (Figure 12).

\subsection{The Regional Landscape Planning Vision}

As shown in Figure 13, the regional landscape planning vision is comprised of three components: the regional extended EN, agricultural land uses, and urbanization areas. Roughly, the broadened regional EN covers $48 \%$ of the entire study area, while agricultural lands comprise one third, and built-up areas comprise one sixth. Certainly, the percentages of the three components will change in the future, with an increase in urbanization areas and a reduction in the other two components.

These ENs, agricultural lands, and urbanization areas are embedded within 


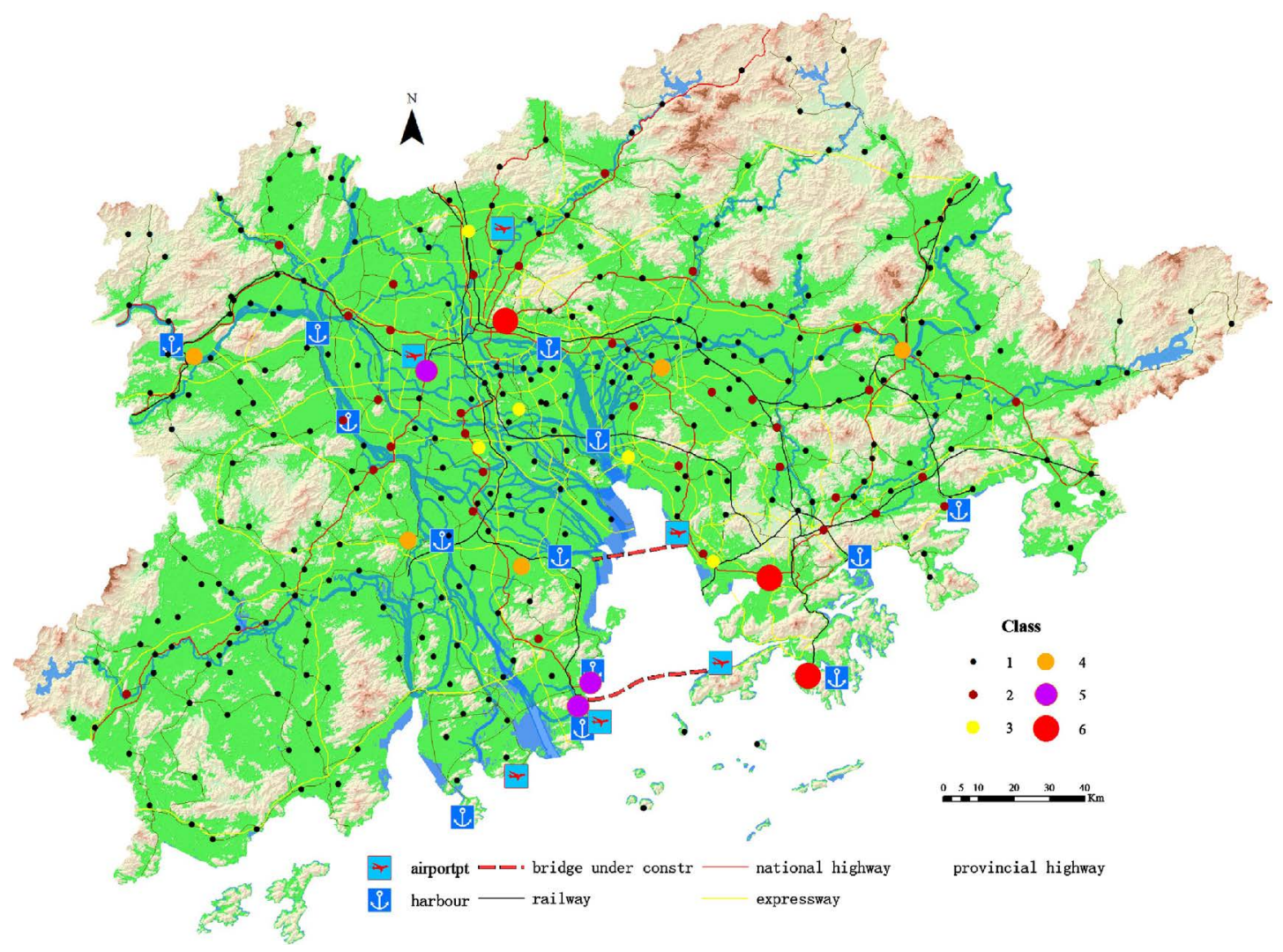

Figure 11. The Greater PRD urban network map.

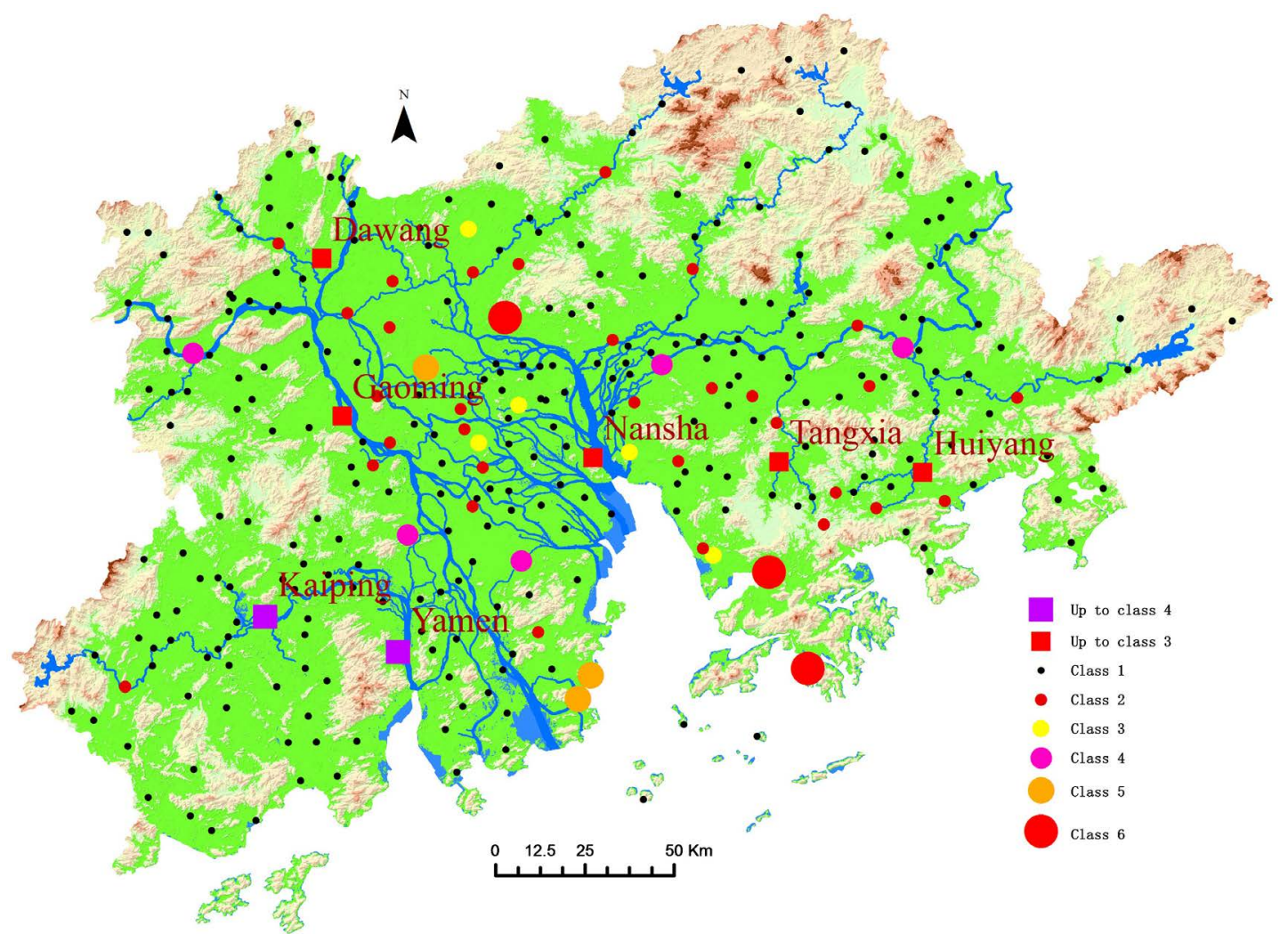

Figure 12. Distribution of central places after upgrading within Greater PRD. 


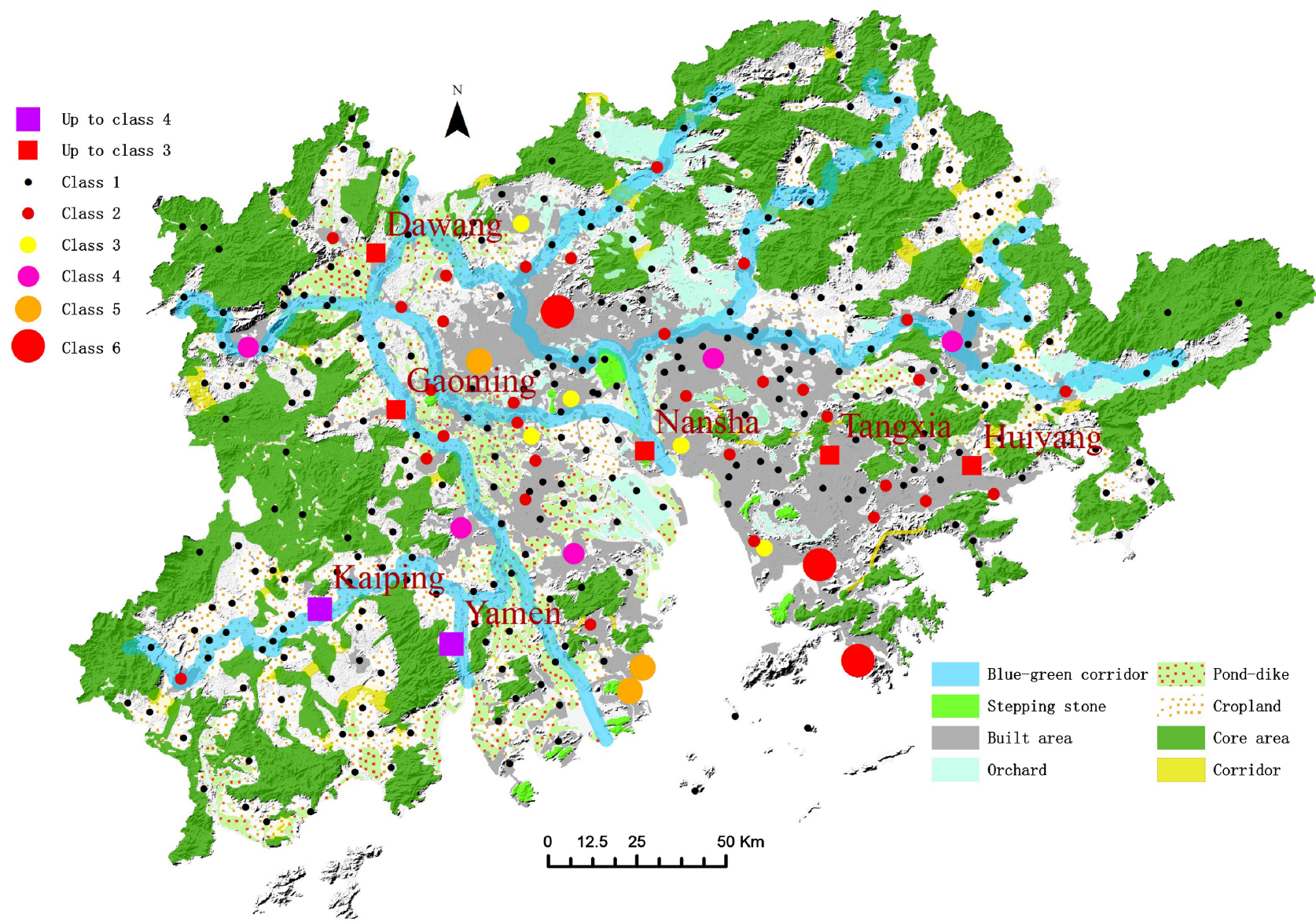

Figure 13. The Greater PRD landscape planning vision based on ecological network and central place theory.

the "urban region" framework of the landscape ecology perspective. The two cores (the Guangzhou and Hong Kong metropolises) serve as urbanizing centers. Landscape planning and management strategy implementation occur within the urban-region rings. The regional EN functions as a backbone for landscape planning strategies. It is suggested that this EN must be strictly protected and enhanced in the future. Urbanization should primarily focus on the seven proposed settlements (CPs) to be upgraded and should utilize a densified rather than spreading development pattern. Agricultural lands should be protected as much as possible, especially primary farm land (Figure 13).

\section{Discussion}

Forman's "urban region" concept appears to be a promising approach because it constitutes, at least to an extent, a framework that harmonizes human development and nature conservation processes.

The GPRD is a good location to use for an empirical examination and framework. A holistic construction of this urban region landscape mosaic should include nature protection landscapes (ENs), agricultural land uses, and human development land uses (villages, towns, cities, and transportation and information infrastructure). To my knowledge, this is the first study that attempts to inte- 
grate a detailed urbanization model and a landscape ecological protection strategy on a large regional scale.

Traditionally, CPT has been considered suitable only for applications in inland, flat, terrestrial areas where the population, resources, and physiographical conditions are evenly distributed. However, there is almost no place on the earth's surface where these conditions are satisfied. In addition, CPT has been considered outdated due to changes such as globalization and the development of an advanced service economy. However, the Christallerian CPT is not entirely useless and it may be used to explain human activities, at least for certain regions where the geographic conditions satisfy the basic classical CPT restrictions.

Agriculture and settlement developments within the GPRD have evolved for more than 3000 thousand years. Although historical fluctuations have been observed, the distribution of the human population and economic activities in this region have specific characteristics caused by various factors, including physical, socioeconomic, and geographic elements. However, the effect of the geographic location is fundamental. From a geographic perspective, the central place locations are paramount in determining human activities. Within the GPRD, particularly the approximately $15,000 \mathrm{~km}^{2}$ inner sub-region, which is mainly plains and small hills, classical CPT principles are still useful for inferring human settlement behaviors. Furthermore, with the modernization of transportation technologies, the influence of inland water bodies and obstacles presented by coastal sea water zones may be drastically reduced. All of these factors imply the feasibility of applying CPT in planning the urban development of the GPRD.

Although the CPI suggests that the Shenzhen metropolis shares a similar importance with the Guangzhou and Hong Kong metropolises, there are several reasons why it can not function at the same level. First, the GDP composition in Shenzhen is relatively low compared with that of Hong Kong, where a large portion of the productivity may be attributed to advanced service industries. Second, institutional headquarters are primarily located in Hong Kong rather than Shenzhen. Thus, the traditional growth poles, Hong Kong and Guangzhou, were chosen as the top CPs that control the urban development system within the GPRD.

\section{Conclusions}

This paper proposed a regional land-use spatial development framework based on landscape ecology's "urban region" concept, which, in turn, employs EN theory to design natural system protection schemes and uses classical CPT principles to arrange urban development strategies. The emphasis is placed on the urban-region rings for the purpose of developing regional landscape planning solutions in economically advanced and rapidly developing areas, such as the GPRD.

The mission of building a regional EN is primarily to mitigate landscape degradation and improve landscape connectivity. To develop the EN, we assumed 
a structural approach based on GIS spatial analysis using various physiographic and socioeconomic data, instead of the target species approaches that have been used by numerous ecologists.

Undoubtedly, the Formanian "urban region" concept is a good approach to regional landscape planning, especially indensely urbanized areas. However, this study enhances the idea through the network approach, that is, arranging nature protection landscapes through the EN designation and addressing urbanization strategies through the urban network approach using CPT principles.

This approach is untested and will require modification and improvement. However, this is a good choice for regional land-use strategy studies because it integrates human development and nature protection. Further studies that pursue functional approaches through agents such as target species in order to construct ENs and import location theories for urbanization solutions are needed.

\section{Conflicts of Interest}

The authors declare no conflicts of interest regarding the publication of this paper.

\section{References}

[1] Geddes, P. (1915) Cities in Evolution. Williams and Norgate, London.

[2] McHarg, I.L. (1969) Design with Nature. Natural History Press, Garden City, NJ, USA.

[3] Naveh, Z. (2000) What Is Holistic Landscape Ecology? A Conceptual Introduction. Landscape and Urban Planning, 50, 7-26. https://doi.org/10.1016/S0169-2046(00)00077-3

[4] Forman, R.T.T. (1995) Land Mosaics: The Ecology of Landscapes and Regions. Cambridge University Press, Cambridge. https://doi.org/10.1017/9781107050327

[5] Forman, R.T.T. (2008) Urban Regions: Ecology and Planning Beyond the City. Cambridge University Press, Cambridge.

https://doi.org/10.1017/CBO9780511754982

[6] Battisti, C. (2013) Ecological Network Planning-From Paradigms to Design and Back: A Cautionary Note. Journal of Land Use Science, 8, 215-223. https://doi.org/10.1080/1747423X.2011.639098

[7] Boitani, L., Falcucci, A., Maiorano, L. and Rondinini, C. (2007) Ecological Networks as Conceptual Frameworks or Operational Tools in Conservation. Conservation Biology, 21, 1414-1422. https://doi.org/10.1111/j.1523-1739.2007.00828.x

[8] Hepcan, C.C. and Ozkan, M.B. (2011) Establishing Ecological Networks for Habitat Conservation in the Case of Çesme-Urla Peninsula, Turkey. Environmental Monitoring and Assessment, 174, 157-170. https://doi.org/10.1007/s10661-010-1447-y

[9] Jongman, R.H.G. (2003) Ecological Networks and Greenways in Europe: Reasoning and Concepts. Journal of Environmental Science, 15, 173-181.

[10] Opdam, P., Steingrover, E. and Van Rooij, S. (2006) Ecological Networks: A Spatial Concept for Multi-Actor Planning of Sustainable Landscapes. Landscape and Urban Planning, 75, 322-332. https://doi.org/10.1016/j.landurbplan.2005.02.015

[11] Hall, P. and Pain, K. (2006) The Polycentric Metropolis: Learning from Mega-City Regions in Europe. Earthscan, London. 
[12] Hall, P. (2009) Looking Backward, Looking Forward: The City Region of the Mid-21st Century. Regional Studies, 43, 803-817. https://doi.org/10.1080/00343400903039673

[13] Davoudi, S. (2008) Conceptions of the City-Region: A Critical Review. Proceedings of the Institution of Civil Engineers-Urban Design and Planning, 161, 51-60. https://doi.org/10.1680/udap.2008.161.2.51

[14] Parr, J. (2005) Perspectives on the City-Region. Regional Studies, 39, 555-566. https://doi.org/10.1080/00343400500151798

[15] Rodríguez-Pose, A. (2008) The Rise of the "City-Region" Concept and Its Development Policy Implications. European Planning Studies, 16, 1025-1046. https://doi.org/10.1080/09654310802315567

[16] Camagni, R. and Salone, C. (1993) Network Urbanstructures in Northern Italy: Elements for a Theoretical Framework. Urban Studies, 30, 1053-1064. https://doi.org/10.1080/00420989320080941

[17] Batten, D. (1995) Network Cities: Creative Urban Agglomerations for the 21st Century. Urban Studies, 32, 313-327. https://doi.org/10.1080/00420989550013103

[18] Meijers, E. (2007) From Central Place to Network Model: Theory and Evidence of a Paradigm Change. Tijdschrift Voor Economische en Sociale Geografie, 98, 245-259. https://doi.org/10.1111/j.1467-9663.2007.00394.x

[19] Mulligan, G.F., Partridge, M.D. and Carruthers, J.I. (2012) Central Place Theory and Its Reemergence in Regional Science. The Annals of Regional Science, 48, 405-431. https://doi.org/10.1007/s00168-011-0496-7

[20] Parr, J. (2002) The Location of Economic Activity: Central Place Theory and the Wider Urban System. In: McCann, P., Ed., Industrial Location Economics, Edward Elgar Publishing House, Cheltenham, 32-82.

[21] Agnew, J. (1999) Regions on the Mind Do Not Equal Regions of the Mind. Progress in Human Geography, 23, 91-96.

[22] Hart, J.F. (1982) The Highest Form of the Geographer's Art. Annals of the American Association of Geographers, 72, 1-29.

[23] Gregory, D., Johnston, R., Pratt, G., Watts, M. and Whatmore, S. (2009) Region. In: The Dictionary of Human Geography, 5th Edition, Blackwell, Oxford, 630-632.

[24] Paasi, A. (2009) The Resurgence of the "Region" and "Regional Identity": Theoretical Perspectives and Empirical Observations on Regional Dynamics in Europe. Review of International Studies, 35, 121-146.

[25] Suorsa, K. (2014) The Concept of "Region" in Research on Regional Innovation Systems. Norwegian Journal of Geography (Norsk Geografisk Tidsskrift), 68, 207-215.

[26] Gottmann, J. (1961) Megalopolis: The Urbanized Northeastern Seaboard of the United States. Twentieth Century Fund, New York.

[27] Pannell, C.W. and Loughlin, P.H. (2015) Macau's Role as a Recreation/Tourist Center in the Pearl River Delta City-Region. Urban Geography, 36, 883-904.

[28] Castells, M. (2000) The Rise of the Network Society. Blackwell, Oxford.

[29] America (2050). http://www.america2050.org/content/megaregions.html

[30] Dewar, M. and Epstein, D. (2007) Planning for Megaregions in the United States. Journal of Planning Literature, 22, 118-124.

[31] Marull, J., Galletto, V., Domene, E. and Trullén, J. (2013) Emerging Megaregion: A New Spatial Scale to Explore Urban Sustainability. Land Use Policy, 34, 353-366. 
[32] Todorovich, P. (2009) America's Emerging Megaregions and Implications for a National Growth Strategy. International Journal of Public Sector Management, 22, 221-234.

[33] Kloosterman, R. and Musterd, S. (2001) The Polycentric Urban Region: Towards a Research Agenda. Urban Studies, 38, 623-633.

[34] Meijers, E. (2005) Polycentric Urban Regions and the Quest for Synergy: Is a Network of Cities More than the Sum of the Parts? Urban Studies, 42, 765-781.

[35] Bie, J., Jong, M.D. and Derudder, B. (2015) Greater Pearl River Delta: Historical Evolution towards a Global City-Region. Journal of Urban Technology, 22, 103-123.

[36] National Bureau of Statistics of China (2016) China Statistical Yearbook 2015.

[37] Guangdong Provincial Government (2016) Guangdong Statistical Yearbook 2015.

[38] Guo, Y. and Liu, Y. (2017) Connecting Regional Landscapes by Ecological Networks in the Greater Pearl River Delta. Landscape and Ecological Engineering, 13, 265-278.

[39] Théau, J., Bernier, A. and Fournier, R.A. (2015) An Evaluation Framework Based on Sustainability-Related Indicators for the Comparison of Conceptual Approaches for Ecological Networks. Ecological Indicators, 52, 444-457.

[40] Jongman, R.H.G. (2004) Ecological Networks and Greenways: Concept, Design and Implementation. Cambridge University Press, Cambridge. 